ISSN:

Print - $2277-078 \mathrm{X}$

Online - $2315-747 \mathrm{X}$

(c) UNAAB 2017

Joumal of

Humanities, Social

Sciences and Creative Arts

\title{
MANAGEMENT OF ETHNO-LINGUISTIC CONFLICT: A COMPARATIVE ANALYSIS OF BELGIAN AND NIGERIAN MODELS
}

\author{
T. OLAIFA., B. SOTILOYE, I. I. DARE \\ Department of Communication and General Studies Federal University of Agriculture, \\ Abeokuta. Nigeria. \\ Corresponding Author. topeolaifa@ gmail.com; Tel: +234 8060171676
}

\begin{abstract}
The spate of violent conflict all over the world since the end of the cold war has been chiefly engineered by ethno-linguistic supremacy based on prevalent ethnic pluralism. Ethno-linguistic pluralism is a conflict issue in Nigeria and it has antecedents of major conflicts trailing its existence. Ethnolinguistic conflicts have been on the rise since the commencement of the Fourth Republic basically due to the liberalisation of the political space and this has resulted in violent conflicts claiming lives and wantonly destroying property. Most of the strategies deployed to resolve ethno-linguistic conflicts in Nigeria are often unable to diagnose accurately the nature of the conflicts and the resolve the main issues causing them. Therefore most of the conflicts become intractable. However, Nigeria is not an isolated case as some other nations around the world are either battling with ideas to resolve the numerous conflicts it has generated or have evolved home-grown mechanisms to manage the ethnolinguistic challenges it has posed. This paper seeks to highlight ethno-linguistic conflict issues in Belgium and the strategies deployed in resolving it and at the same time reflect on the Nigerian experience drawing out unique experiences, similarities and lessons to be learnt from both countries.
\end{abstract}

\section{INTRODUCTION}

It has become a grounded theory that the historical antecedence of nations around the world is embedded in conflict and struggles. Through the combative elements of conflict, nations had been able to stand against repressive laws and enactment. However, although conflict is a characteristic of human existence and its dynamics, it needs to be managed constructively. When associated with violence, destruction and killing, conflict is no longer a healthy part of living. Violent conflict resolves few problems, creates many, and breeds more unhealthy future conflicts.
Recent events around the world have exposed man to the realities of conflict. With the emergent ethnic militia groups and international terrorist organizations such as AlShabab, Al Queeda, Bdko Haram and many dhess the world has come to grasp with the precariousness of its existence and is deploying both national and transnational machinery into putting them into extinction.

Belgium has a long history of language division but English is widely accepted. If you speak French to a Flemish person, he or she might be offended. If you happen to speak Flemish or Dutch to a French-speaking Bruxellois he will most certainly answer you 
in French with some disdain (Beheydt, of instruction or medium of nursery and 1995).

lower primary education, though later it became a subject of controversy among educa-

Brussels has its own dialect, Bruxellois, that is primarily Flemish in origin but in the course of time, French became dominant. Therefore, very few people now speak this interesting dialect. It is hard to get it right, and even Flemish- and French-speaking people in Brussels will sometimes use English to communicate with each other" (Sattin 2000). As things are, "rivalry endures between those who speak Flemish and those who speak French" (Sattin, 2000). Nigeria as a nation has undergone periods of transition basically from its decolonization in the recent past. The changes in the language policy should include "three types of policy: official language policy, educational language policy and general language policy; a three-way paradigm to which Bamgbose (1991:111) also added a fourth which is the distinction between levels of decision making. The republican constitution of 1963 retained the independent Nigeria language policy that was established in 1954.

However, in article 51 and 53 of the 1979 and 1989 constitutions respectively recommended a new policy of tri-lingualism, i.e, that the business of the National Assembly in Nigeria to be conducted primarily in English, and in three additional crucial languages when adequate arrangement could be made. This legislation increased the status of indigenous languages in the country.

In 1977, the new prime language policy was introduced and was subsequently revised in 1981. The policy also gained prominence in the 1995 and 1998 national educational policy. According to the policy, the use of the child's mother-tongue or the language of the immediate environment as the language tionists and linguists such that by 1991, a team of Nigeria linguists recommended that the language for educational instructions should be the language that represent the 'wider community and not a language spoken by an ethnic community'. Their recommendation gave the monopoly of language to English Language as it represents the only language that is spoken by vast majority.

These two multi-lingual communities have a lot in common in the area of ethno-linguistic conflict and that has stirred-up the interest of this study.

\section{Ethno-linguistic Identity theory}

Perception is a crucial factor in conflict as it is a strong driver of conflict progression and dynamics. Pruitt and Rubin (1986:4) define conflict as a "perceived divergence of interest". A conflict issue becomes real when a party feels and declares it to be. Cargile, Giles and Clement (1995) believe that, 'certainly there are very "real" indicators of conflict, such as demonstrations and war, but the essence of conflict is a situation or relationship viewed as such'.

The essence of the conflict situation is driven by language employed in expressing its details and this consequently defines its dynamics and intensity. Language is deployed in identifying the both the 'in' and 'out' groups and the choice of narratives that would define the intensity of the issues in conflict. Cargile tal (1995) capture their finding thus:

By investigating the ways in which people use language, both as an explicit vehicle for ideas and as an implicit expression of mem- 
bership and identity, we have seen that language clearly plays a number of important roles in episodes of human conflict. Because conflict is a status assigned to situations based on people's subjective perceptions, language is a critical forum of debate and influence that dominates such perceptions. Racial and ethnic conflict also depends on language to help establish who belong to which groups.

By investigating the ways in which people use language, both as an explicit vehicle for ideas and as an implicit expression of membership and identity, we have seen that language clearly plays a number of important roles in episodes of human conflict. Because conflict is a status assigned to situations based on people's subjective perceptions, language is a critical forum of debate and influence that dominates such perceptions. Racial and ethnic conflict also depends on language to help establish who belong to which groups.

Language is equally an active organ of ethnic boundary delineation. It is common to have people of same ethnic grouping occupying the same geographical space and this distinguishes and sometimes, demarcates them from people of other languages. An example of this can be found in Nigeria, a multi-linguistic country where the Yoruba occupies the Western part, the Igbo in the East and the Hausa in the Northern hemisphere of the country. The tribes are located along geographical demarcations within the country thereby intensifying the ethnic dominance perception.

In ethno-linguistic identity when group members try to pass linguistically into the dominant group or try to redefine and revitalize the status of their language, these moves will often be met with resistance. Conflict then takes the form of dominant group members failing to acknowledge the speech of others, upward divergence, or even pejoration. According to Olaifa, Dare, Balogun, Adekunle, Ige and Kayode (2016:45), 'In a multilingual speech communities, there is bound to be a dominant language (high variety) which the majority in such communities speak. Such a language often assumes the status of a language of domination, oppression and suppression exploited by autocratic governments and dominant ethnic groups.

This paper seeks to look at how this theory has played out in the ethno-linguistic conflicts in Belgium and Nigeria to be able to further strengthen the veracity of the theory.

\section{Ethno-linguistics}

This is also referred to as cultural linguistics is a field of linguistics which studies the connection between language and culture, and the way different ethnic groups perceive the world. Ethno-linguistics is the combination between ethnology and linguistics. The former refers to the way of life of an entire community, i.e., all the characteristics which distinguish one community from the other (Ferraro, 2006). Those characteristics make the cultural aspects of a community or a society.

Suffice to say that social conflicts become inevitable due to the fact that different ethnic groups, with their natural and distinguished characteristics, and different cultural perceptions of social phenomenon often cohabit. Ethno-linguistics is the combination between ethnology and linguistics.

\section{Conflict}

Any perceived incompatibility in the pursuit 
of goal or interests is a conflict. It could manifest in break in communication or outright malice, confrontation and violence.

Conflict as a term is derived from the Latin word confligre which means to clash; to engage in a fight. Basically, it alludes to a confrontation between two or more groups over incompatible goals. Conflict is an integral part of human existence. It is a relationship issue, therefore, as long as man continues to pluralise himself on earth, breeding people with different backgrounds, social and political outlooks, economic status, religious and ethnic divergence, there will always be conflict.

Davis Francis simply defines conflict as 'an intrinsic and inevitable part of human existence'. Conflict is a phenomenon that is an important part of human existence and a natural part of our daily lives. If conflict is inevitable, one begins to wonder how it occurs. Onifade, Olaifa, Odozor \& Imhonopi (2015) posit that conflict is the result of perceived, irreconcilable differences between two parties. The parties may be individual or groups within a state or states within the globe.

When those parties have opposing views about how some social, political, religious, cultural or ethnic situations could be organised, conflicts do arise. Conflict is a struggle over values and claims to scarce status, power, and resources in which the aims of the opponents are to neutralise, injure, or eliminate their rivals.

The views expressed above imply that conflict results from the social interaction of people who vie for personal existence in a milieu of scarce resources. The struggle persists for as long as the 'fittest' survives.
Conflict is the expression of disagreement over something important to both (or all) sides of a dispute. Conflict refers to some form of friction, disagreement, or discord arising within a group when the beliefs or actions of one or more members of the group are either resisted by or unacceptable to one or more members of another group (Abdullahi, 2005). Conflict can arise between members of the same group, known as intragroup conflict, or it can occur between members of two or more groups, and involve violence, interpersonal discord, and psychological tension, known as inter-group conflict. Conflict in groups often follows a specific course. Routine group interaction is first disrupted by an initial conflict, often caused by differences of opinion, disagreements between members, or scarcity of resources. At this point, the group is no longer united, and may split into coalitions.

The first important thing to grasp is that it is entirely dependent on the people involved. It depends on their having a particular point of view, which may or may not have independent facts and evidence to support it, and on how they behave when they encounter an opposing point of view.

\section{ISSUES IN CONFLICT}

There are several issues that result in conflict situations. The understanding of these issues puts one at a vantage position in resolving it especially when dealing with people from diverse origins. The issues include the following:

1. Conflicts arise when people compete for the scarce resources (such as territory, jobs and income, housing) when they are not fairly distributed or when there are not enough to go round.

2. Likewise, conflicts arise when the people 
are unhappy with how they are governed. The most common conflicts occur when a particular group wants to be independent from a central government, or when their viewpoint is not represented in the government.

3. Conflicts do occur when people's beliefs clash. Religious and political views are particularly sensitive, because people often depend on these for a sense of identity and belonging. Sometimes the conflict is caused by a religious/ political group being attacked; sometimes it is because the group is eager to spread a particular belief and even enforce it on others.

4. In the same way ethnic differences can cause conflict, or be made to cause it. Again, people's ethnicity gives them a sense of identity and belonging, and it is threats to this sense which can cause violent responses, just as individuals may lash out with angry words or gestures when they feel threatened. Indeed, all kinds of conflict arise when people feel threatened; regardless of whether the threat is real or perceived. It is hard to assuage or reassure people when they are frightened or angry. In recent times, issues surrounding conflicts around the world are often attributed to either ethnic or religious issues but with the turn of event in the 21st century it has been seen that several other issues account for conflict aside ethnic and religious causes.

\section{BACKGROUND TO THE BELGIAN CONFLICT}

In order to examine the language conflict in Belgium, it will be useful to give some historical information. The "language frontier" between the Flemish and the Walloon Communities was traced for the first time in the 4th century, when Franks invaded Belgica (Belgian Gaule) and founded what today is called Flanders. They conserved their Germanic language in this region, but were not able to do so when they had to face the $\mathrm{Gal}$ loroman people who outnumbered them. In the following centuries Belgium underwent many changes as regards language. Two important events that are worthy of note occurred in the course of these centuries:

- In 1794, after the French revolution, Belgium was integrated into the French Empire; Napoleon prohibited the usage of the D utch language and imposed the French Civil Code (Edward and Burgess, n.d).

- After Napoleon's defeat, the Congress of Vienna proclaimed the "Kingdom of the Netherlands" which included Belgium. The new king, a Dutchman, imposed the Dutch language on the entire kingdom. Both Walloon and Flemish people revolted against this D utch authoritarian king, who imposed his language. More revolts took place and led to the creation of an independent Belgium in 1830.

When the Belgian state was created in 1830, the Constitution had provided for a unitary state which soon proved to be unsuited to the ambitions of Flemings (D utch speakers), because only one official language was provided for: French. It should be added that next to Dutch (the language spoken in the Netherlands), French was rightly or wrongly perceived by the ruling elite as a factor in achieving national unity and independence from the Netherlands. Furthermore, following the ideas of the French revolution, French enjoyed great prestige as "the language of reason and civilization." As for the Belgian elite, which was filled with admiration for France, the French language seemed to be the obvious choice, when in fact the 
native language of the majority of Belgians was either a dialectal form of Dutch (Flemish, Brabantish, Limburgish) or one of the idioms derived from Latin (Walloon, Picard, Lorraine.) As regards the city of Brussels, only $15 \%$ of its population was francophone at the time (Satin, 2000).

\section{ORIGIN OF THE LINGUISTIC CONFLICT IN BELGIUM}

The linguistic conflict started in 1840, at which time the French language prevailed in most of the country's social interactions (Espersen, 2012). In fact, all schools, the government and municipal services, courts, etc. used only French in official documents. French was the language of the dominant classes, both Flemish and Walloon. The aristocrat and the bourgeoisie spoke French, while the common people spoke Flemish, Walloon, Brabantish, or various other local dialects.

In successive steps the defenders of the Dutch language succeeded in imposing Dutch language in the country's official life. In 1880, 50\% of the population of Brussels was Flemish, but it was not until 1883 that Dutch - called "Flemish" in French texts was allowed in primary education (which was of limited application) and until 1889 that it was accepted in courts (for oral testimonies). In 1894 the $\mathrm{DeVriendt-Coremans}$ law ranked it next to French as an "official language". However, in reality French remained the language primarily used to all intents and purposes in the Belgian state. This is why the defenders of Flemish (whom their adversaries called "Flamingants" - a French term denoting Flemish nationalists) changed the language used at the University of Ghent from French to D utch; the Flemish upper middle class, which remained francophile, was against this change. This is when the term "Wallingant" - which denotes a Walloon separatist- also appeared, modelled on the term "Flamingant"; both terms, strongly derogatory, denoted the political activists who advanced mainly nationalistic and regionalistic interests.

In 1921 the Belgian government decided to create three linguistic regions:

1) Flemish part in the North (where French could still be used);

2) French part in the South (where Dutch would not be used despite the significant presence of Flemings);

3) bilingual part (Brussels), although the great majority of Brussels inhabitants spoke Dutch (Espersen, 2012).

The law of July 14, 1932 prescribed D utch to be the official language in Flanders, French to be the official language in Wallonia, and German to be the official language in the region of Eupen and Saint-Vith (a Germanspeaking region). Only the city of Brussels, surrounded by Flemish territory, was declared bilingual. Thus French and D utch became the two co-official languages of the Belgian state (Tollefson, 1991)

Bilingualism in Brussels represented a victory for Francophones because this status gave them the possibility of still "gaining ground" on Flemings, who had become a minority. The law of 1921 was supposed to protect the Francophones, whereas today it favours the Dutch speakers. According to this law the language boundary should change following decennial language censuses. The university of Ghent became exclusively Dutchspeaking. Nevertheless, the law still allowed Walloons to trick Flemings out of some of their territory every ten years.

Since the sixties the revival of community 
conflicts between Flemings and Walloons dominated political life. The compromise of a linguistic boundary moving according to decennial censuses was no longer agreeable to Flemings, who watched the Walloons increasing their territory by a few kilometres every ten years. As a result, Flemings set a goal to establish a definitive linguistic boundary.

Establishing a definitive language boundary meant that Walloons would no longer obtain any Flemish territory, and vice-versa. Therefore, the Flemish tried to suppress the decennial language census because it should no longer play a role in determining this boundary. Thus the census of 1960 was boycotted by roughly 300 Flemish mayors, apparently because they feared that the census would prove the existence of Frenchspeaking minorities in their communes.

\section{THE LANGUAGE SITUATION IN BELGIUM}

According to the Constitution of 1994, Belgium consists of three economically autonomous regions: Wallonia in the South, Flanders in the North, and Brussels (which is situated in Flanders); three language communities: the French Community, the Flemish Community, and the German-speaking Community; and finally four linguistic regions: the Dutch-language region, the French-language region, the Germanlanguage region, and the bilingual region of Brussels.

- The region of Flanders covers $44 \%$ of Belgium's surface and comprises $57.6 \%$ of the Belgian population (5.9 million inhabitants). The inhabitants of this region speak mainly Dutch, as well as various dialects of Dutch (such as Flemish).

- Wallonia covers $55 \%$ of Belgium's surface and comprises $32.4 \%$ of the population (3.3 million inhabitants). Walloons speak mainly French, but some speak dialects, such as Walloon.

- The region of Brussels, situated in the Flemish province of Brabant, comprises 9.3\% of the Belgian population (960 000 inhabitants). $70 \%$ of these inhabitants speak French, 10\% speak Dutch, and 20\% speak other languages (such as Italian, Spanish, Turkish, Arabic, etc.) (E spersen, 2012).

Since 1961 it is forbidden to conduct a language census in Brussels. It is therefore very difficult to calculate the exact percentages of French- and Dutch-speaking people in this city. The statistical results provided in a study conducted by Laval University (http:/ / www.tlfq.ulaval.ca/ axl/ europe/ belgiqueacc.htm) and in other studies come from the lists of voters in regional elections which cannot reflect the truth, since there are Belgium residents who do not speak either of the two languages, but still register to vote on one of the two lists.

It is not the regions, but the Communities that issue decrees concerning language. The French Community corresponds to the region of Wallonia and to the bilingual region of Brussels (for those who have chosen French as "language of administration" and/ or "language of education".) The Flemish community corresponds to Flanders and the region of Brussels (for those who have chosen Dutch to be their "language of education" and "language of administration"). There is also a German-speaking Community, which corresponds to the Germanspeaking region (actually situated in Wallonia), but it cannot issue laws or decrees related to language, according to the Constitution. 
Belgium's language policy is defined in particular in the following articles of the Constitution of 1994: 2, 4, 30, 43, 54, 67, 68, 99, $115,118,121,123,127,128,129,130,135$, $136,137,138,139,175,176,178$, and 189, as well as in a big number of language laws, among which we find:

- the royal decree of 6 January 1933 regarding the languages used in administration

- the law of 15 June 1935 regarding the languages used in the judicial sector

- the law of 30 July 1938 regarding the languages used in the army

- the law of 2 July 1954 regarding the languages used in administration

- the law of 30 July 1963 regarding the languages used in education

- the law of 30 November 1966 regarding language exams

- the special law of 8 A ugust 1980 regarding constitutional reforms

- the law of 5 October 1988 regarding the languages used in the judicial sector

- the special law of 12 January 1989 regarding municipal institutions in Brussels.

Official communication in a single language constitutes a violation to the federal law. This is why poster advertising, road signs, etc. in Brussels always include both languages: Dutch and French. Citizens are allowed to use the language of their choice, but this is not the case for government institutions.

As regards languages used in the federal government, according to article 99 of the Belgian constitution, the council of ministers must have as many French-speaking ministers as D utch-speaking. The same balance $(50 \%$ French and 50\% Dutchspeaking) applies to the Court of Arbitration, the Council of State, the Court of Cas- sation, the Supreme Council of Justice, and other government organizations.

While communities and regions have only one Council each, the federal state has a federal parliament and a senate. According to article 43 of the Constitution, in the federal parliament and the senate, deputies and senators are divided in two language groups: French- and Dutch-speaking (proportional representation). This proportional representation favours the Flemish, who, as a result, outnumbered the Walloons both in the federal parliament and the senate. In the past, in order to avoid unfair decisions regarding language and culture-related laws, these laws were adopted according to the principle of double majority. However, in case of disagreement by the deputies or senators, decisions took very long to make and language laws were often forgotten or took years to adopt. This is why today, according to article 107, in order for a law to be adopted, the majority of votes in each language group must be reached, and the total number of positive votes must reach two thirds of all vote casts.

In the justice system, the law that determines the languages used is that of 15 June 1935; it has been modified several times, but still applies today. According to this law, only Dutch must be used in Flanders, and French in Wallonia and the German-speaking region. The law provides the following options in case the defendant does not speak the language used by the court:

a) He (the defendant) may accept that the process take place in another language (French, Dutch, or G erman);

b) He may ask for an interpreter;

c) He may ask for the process to take place in a court of another province where his lan- 
guage is spoken.

The same law requires that in Brussels, two thirds of judges be bilingual.

In the administration sector, the law of 18 July 1966 states that federal administration must function in French in Wallonia, in Dutch in Flanders, and in French and Dutch in Brussels. According to article 19, public administration must use the language of the person that is using their services. As far as documents are concerned, they are issued in all three official languages (French, Dutch, and G erman).

As regards public poster advertising and road signs, these are displayed in French in Wallonia and in Dutch in Flanders. Thus, French toponyms are written in Dutch in Flanders; similarly, French names are used in Wallonia for Flemish toponyms. As an example, the name used in Flanders for Liège is Luik, which may confuse those who are not familiar with the name of this city in both languages. As mentioned above, poster advertising and road signs are displayed in both languages in Brussels. Thus, we see street names written in French and in Dutch.

As for which language is used first on road signs, this is determined by the region in which a town is located; for example, a sign for the city of Liège (which is situated in Wallonia) would display "Liège/ Luik", while a sign for the Flemish city of Antwerp would display "Antwerpen/ Anvers".

In Belgium higher education, the language laws of 1962 determines the language used in teaching. In Wallonia, from the fifth class of primary school, D utch, English, or German classes may be taught, depending on parents' demands. In secondary school, from the first year a second language is compulsory (D utch, English, or German). In Flanders, from the fifth class of primary school, a second language may be taught (French or English, again depending on parents' demands); in the first year of secondary school, both French and English are taught. In Brussels the situation is different: from the third year of primary school, a second language (D utch for French-speakers and French for D utch speakers) is compulsory. It could be inferred from this educational strategy that a significant factor in students' second-language acquisition (SLA) is language planning. Although SLA is affected by individual factors such as motivation (neoclassical approach, as described by Tollefson (1991), studies on language acquisition in Belgium concern mainly language planning strategies, historical, social and political factors, which shows that it is the historical-structural approach that is in use

\section{RESOLUTION OF THE CONFLICT}

The existence of language-related laws and strategies does not guarantee that these laws and strategies will be respected. How does the Belgian state ensure that the appropriate language will be used in each situation? The law of 18 July 1966 regarding the use of languages in administration provided for a committee of eleven members (five Frenchspeaking, five D utch-speaking, and one G erman-speaking member) appointed by the king for 4 years.

This is the Permanent Commission for Language Control (Commission Prmanente de Contrôle Linguistique) and its purpose is to monitor the application of language-related laws. This commission is divided in two parts: a Dutch section that is responsible for Flanders, and a French section responsible for Wallonia and for the German-speaking cantons. These two sections have to collaborate when it comes to the city of Brussels. It 
is this committee to which citizens can address their complaints regarding the use of languages in public services.

What is the motivation for such a complex language policy? In his study of Australia's language policy, Lo Bianco (1987) examines why a move towards a national language policy is necessary. Similarly we should explain the purpose of a language policy in Belgium. Complex language legislation was established in Belgium in order to guarantee members of the Dutch-speaking and the French-speaking community the use of their own language in administration and municipal and regional services. In Brussels, where the two linguistic groups coexist, the language policy is necessary in order for citizens' linguistic rights not to be violated. Such rights, as mentioned above, include the choice of language (either Dutch of French) in which one's children will be educated, the right to use one's native language in administration, the possibility of interacting with a judge who speaks a citizen's native language in court, the possibility of living in a city where one can understand road signs and subway maps, etc.

Examining the micro aspect of the language situation in Belgium, can it be said that the language policy is successful as regarding the social interaction between Belgium's two main language groups? Is there really rivalry between the Dutch-speaking and the French-speaking Belgians? Do these two groups really communicate in English with each other, or do they try to learn the other group's language? The study conducted at Laval University states that according to the Flemish daily paper, Standard, only 16.5\% of the Flemish people have a very good knowledge of the French language, although in fact $60 \%$ of them are able to un- derstand it and speak it. On the other hand, only $6 \%$ to $7 \%$ of the French-speaking Belgians speak D utch.

What does this mean? O ne point of view is that there is indeed rivalry between these two groups of people. Another point of view could be that these people are desperately trying to defend and preserve their linguistic and cultural identity, which they feel is threatened in this bilingual, or rather multilingual country called Belgium. In his article "Belgium: society, character and culture. An essay on the Belgian identity", Heylighen (1994), a Belgian scientist, observed that "there have been a lot of political conflicts between the two main linguistic communities, but the language problem, which is the issue that has received most publicity outside Belgium, is much less important than it seems. Since the federalization of the state the linguistic conflicts seem to have very much diminished, now that politicians are no longer capable to blame difficulties on the "other side". There have never been any real conflicts between Belgian (Walloon and Flemish) people, as opposed to conflicts between Belgian politicians.

The best illustration of that is that even during the most heated episodes, no one has ever been killed or seriously injured in clashes connected with the linguistic conflict. It suffices to consider similar situations in other countries where conflicts exist between cultural or linguistic communities (e.g. Yugoslavia, Canada, Northern Ireland) to conclude that such peacefulness is not the common rule."

The above point of view is very close to that of most Flemings and Walloons. Yes, there is a language conflict, but it is not as serious as many people (mostly non-Belgians) be- 
lieve, and it certainly does not prevent Belgium from being a nation. Meanwhile, the Belgian government has put in place measures, such as the prohibition of language census in Brussels, to eliminate language conflicts. Indeed, the so-called linguistic conflict is not obvious in everyday life.

\section{NIGE RIA'S ETHNIC PLURAL- ISM AND ITS ATTENDANT CONFLICTS}

The existence of Nigeria as a nation has constantly been bedevilled with conflict of diverse nature and origin. Since independence in 1960, the nation has witnessed large scale conflict eruptions culminating into violence of various degrees and the utmost, a never to be forgotten civil war which almost tore the budding sovereign entity into shreds.

The nation Nigeria was born out of a conglomeration of about seven hundred ethnic groups, three major tribes, over 700 religious groups, three major religious and divergent socio-cultural lineages. For this reason alone, the slogan 'Unity in Diversity' is an apt description of the nation, Nigeria's situation.

All these stemmed from its multidimensional plurality. Nigeria as described by Ogunyemi (2009) while trying to quote the exact number of languages in Nigeria stated that is a country where there is a lot of controversy on the actual number of indigenous languages. G reenberg (1971) puts the figure at 248, Bamgbose (1976) estimated it at 400 while Hoffman (1975) puts it between 400 and 513 living. Oyetayo (2006) presented a more comprehensive analysis of the Nigerian linguistic situation by identifying 510 living languages and nine extinct languages. This brings the total number of indigenous languages (both living and extinct) in Nigeria to 519. Thus Oyetade (1995) aptly describes Nigeria as a linguistically fragmented country.

Of significance is the conflict which arises as a result of divergent languages. Politically, Arua (2003:135) stated that, "we cannot promptly specify the number of languages spoken in Nigeria" as a nation. The multiplicity of languages in Nigeria is so obvious and egregious that languages of people living within a 25 kilometre radius are massively different and incomprehensible to one another (D anladi, 2013). The implication of this complex language situation is the absence of established effective communications between the ethnic groups, which becomes the basis not only for bigotry and hatred but for resorting to the use of English as a predominantly official language. It also implies that the choice of any of the three indigenous languages as a national language certainly will deteriorate to disintegration or unpleasant feelings.

Based on the facts enumerated above, it is not surprising therefore that a conglomeration of socio-cultural and ethnic groups like Nigeria, experience conflict of such magnitude and frequency. Before the advent of the British colonialist in Nigeria, there were several existing cultures and ethnic groups in the country. All these cultures had an already established means of communicating and expressing themselves.

They had fully developed a language system that has helped them develop their societies. The advent of the British colonialist in Nigeria paved the way for the demise or relegation of these indigenous languages. The British colonial policy of indirect rule also 
brought with it a transfer of the English language which was taught to Nigerians for administrative convenience and messengerial effectiveness. D ecades after the departure of the British colonial government, English language has become the official language of the country.

The institutionalisation of English as the lingua franca of the country has substituted the use of the indigenous languages in almost all spheres of the nation's sociopolitical and economic life. It is no news that red alerts had been signalled from various quarters as the indigenous languages are fast going into extinction due to the wide use of English language. Even youths in the country attach less significance to the learning and speaking of indigenous languages.

This could be partly blamed on the rise of globalization and ineptness on the part of the policy makers. This lasciviousness can be explained by the lack of interest shown by secondary school students in offering the languages in their secondary school examination. Also in the political terrain, it has been argued that the use of indigenous languages in the legislative chambers should be encouraged. To delve into the politics of language in Nigeria, it would be necessary to highlight the face of language policy in the country.

Nigeria as a nation has undergone periods of transition basically from its decolonization in the recent past. The changes in the language policy should include "three types of policy: official language policy, educational language policy and general language policy; a three-way paradigm to which Bamgbose (1991:111) also added a fourth which is the distinction between levels of decision making. The republican constitution of
1963 retained the independent Nigeria language policy that was established in 1954. However, in article 51 an d 53 of the 1979 and 1989 constitutions respectively recommended a new policy of tri-lingualism, i.e, that the business of the National Assembly in Nigeria to be conducted primarily in English, and in three additional crucial languages when adequate arrangement could be made. This legislation increased the status of indigenous languages in the country.

In 1977, the new prime language policy was introduced and was subsequently revised in 1981. The policy also gained prominence in the 1995 and 1998 national educational policy. According to the policy, the use of the child's mother-tongue or the language of the immediate environment as the language of instruction or medium of nursery and lower primary education, though later it became a subject of controversy among educationists and linguists such that by 1991, a team of Nigeria linguists recommended that the language for educational instructions should be the language that represent the 'wider community and not a language spoken by an ethnic community'. Their recommendation gave the monopoly of language to English Language as it represents the only language that is spoken by vast majority.

It is clear from the constitution that language planning is aimed at making an average Nigerian trilingual: a speaker of English, his mother tongue and an additional Nigerian language (D anladi, 2013). The revision of these policies in 1998 added French as an official language because it was seen as the language of Nigeria's immediate neighbours: Francophone Benin, Chad, Niger and Cameroun and several members of the ECOWAS sub-region (D anladi, 2013). The policy pushes Nigeria in the direction of language shift 
from tri- lingualism to quadri-lingualism. English is the "Official" language, Hausa, Yoruba and Igbo are legal Nigeria's languages to be used officially in schools but the status of English as the official language, especially in high places like national Assembly shifts (D anladi, 2013).

With the implementation of these policies, English language remains a dominant language in the country. Therefore, the continued use of English language has led to the relegation and under development of the indigenous languages in the country. Although, the position of supremacy ascribed to the use of English language as the official; language is understandable in the sense that an attempt to adopt any of the indigenous languages as an official language may be detrimental to the unity of the nation as a whole and also hinder national progress. In other words, having a decentralized language system combine with the adoption of a uniform language that is widely spoken is in the best interest of the country.

The prerogative of usage of these languages depends on the mode of communication and the environment condition where it is been used. For example in Nigeria, marketers, organizations and advertisers are sensitive to the language of the environment where they operate before putting out advertisement or information on the media.

In the northern part of Nigeria, Hausa language is the predominant languages used by the people in the discharge of administrative duties except on strict official basis do they use English language for administrative purposes. While in the south west which is largely occupied by the Yoruba speaking tribe, the use of English language is used majorly in all aspect of their socio-economic and political life. This can be ascribed largely to their level of educational status. It is to be noted that the Yoruba speaking tribe views the use of English language as a way of symbolizing civilization, therefore, relegating their indigenous languages to the background (D anladi, 2013).

Politically, most government press, publications, reviews of the National Assembly are released in English also this is another language shift. However, it is not compulsory for civil servants to communicate in English during official hours but in most cases, public servants choose to speak in their native language with co-workers during administrative functions, especially if there are from the same regions. Furthermore, all official websites of government are in English though, each of the three principal languages also has their sites; this all interpret the trilingualism of their status.

Additionally, the primary reason for increase uses of English in Nigeria is to promote western education and thus provide wider access to social rewards while the earliest motivation for learning another Nigerians language is to allow bilingualism by ensuring meaningful participation in regional collective, economic and political interactions as well as the forces of unification (Danladi, 2013). The Ife six-year primary project (Fafunwa, 1975 and 1990) have helped to establish the viability of the policy for the use of the mother-tongue as a language of instruction in primary education.

\section{CONCLUSION}

Comparing the linguistic situations in Nigeria and Belgium one would be able to assert that the pluralistic nature of these countries is responsible for the bi/ trilingual language approach adopted. As the case was in Belgium, 
it would be chaotic to adopt a single language policy to run in the country considering the diverse ethnic groups existing in the country. One safe means to ensure peace is to enact a language policy that would cater for the several indigenous languages so as not to give prominence to one language over the other. The history of sociopolitical conflict in Belgium has been largely attributed to the continued imposition of the language of the elite class over the minority.

While in Nigeria, ethnic multiplier effect has not been a sweet experience as it is being witnessed on daily basis the danger it poses to the unity of the country as a whole and the economic and social development of the regions. Though there had not a report of language resulting into an escalating, uncontrollable violence but the discrepancy caused can be identified in the incessant change and formulation of language policies especially at the educational level. The adoption of a single language would spell doom for a country that is yet to experience respite from incessant ethno-religious and political violence. Still with the adoption English language as the official language, disagreement erupts in organizations, social circuits, educational sector as to which language should be used in expressing opinions and ideas.

\section{REFERENCES}

Arua, A. E. 2003. Getting Ready to Teach in Primary School. In C. E. Onukaogu, A. E. Arua and O. B. jegede (Eds). Teaching Reading in Nigeria : A Guide to theory and practice in Nigeria. Ibadan : International Reading A ssociation

Abdullahi, A. S 2015. The impact of conflict management on organizational effec- tiveness (A case study : Ministry of higher education of Jordan). European Journal of Business and management.

Bamgbose, A. 1991. Nigeia Language and altural dedepment in Ikara, B.(ed). Lagos: The National Language Center Beheydt, C. (1995). The linguistic situation in new Belgium. In S. Wright (Eds). Language in contact and conflict : contrasting experiences in the Netherlands and Belgium. Cleveland : multilingual matters.

Cargile, Aaron., Howard Giles and Richard Clement 1995. Language, Conflict and Ethnolinguistic Identity Theory.

https://www.academia.edu/21621310/

Lguage conflict and ethnolinguistic ident ity_theory

Danladi, S. S. 2013. language policy : Nigeria and the role of English language in the 21st century Institute of political studies. Faculty of political studies, Charles University in Prague, Czech Republic. European scientific journal vol 9 no 17

Edward, B. S., Burgess, J. R. (nd). The Changing role of OD CS in defense cooperation in armaments: the view from Brussels.

Espersen, M. B 2012. Multilingualism in Belgium and Switzerland. A comparative analysis of the two countries linguistic conflict and the significance of language to national identity. D epartment of international culture and communication studies. Copenhagen Business School.

Fafunwa, A. B. 1989. Education in Mother Tongue theIfe- primary elucation research projet (1970 - 1978). Ibadan; University Press

Fafunwa, A.B. 1982. "An integrated Prima- 
ry School Curriculum Skill in Nigeria: A Six -Y ear Project". In Afolayan, A. (ed). Youba Langrage and Literature Ile-Ife: University of Ife Press.

Fishman, J., Das Gupta, J., Jemudd, B., and Rubin, J. 1977, 'Research outline for comparative studies of language planning in Rubin, J., Jernudd, B., Das Gupta, J., Fishman, J., and Ferguson, C. (eds) (1977) Langrage plaming proceses The Hague: Mouton.

Greenberg, T. 1971. Attitude of Children from D eprived Environment toward Achievement Related Concepts. Jaumal of Edurational Resarch Heylighen, F. (1994). Belgium: society, character and culture. http:/ / pespmc1.vub.ac.be/ BelgCul2.html accessed on 7 July 2015.

H offman, C.1975 TheLangrages of Nigria by LangrageFamilies Ibadan: Ibadan University Press

Kingdom of Belgium: Law concerning the use of languages in administration, 18 July 1966. URL: http:/ / www.tlfq.ulaval.ca/ axl/ europe/ belgique66.htm

Kingdomof Belgium Constitution of 19 94. URL: http:/ / www.tlfq.ulaval.ca/ axl/ europe/ belgiqueetatconst.htm. Retrieved 30th November, 2015

Luke, A., McHoul, A., and Mey, J. L. 1990 ' $O \mathrm{n}$ the limits of language planning: Class, state and power' In Baldauf, R. and Luke, A. (eds) Language planing and eduration in
Australasia and the Sath Paific Clevedon: Multilingual Matters

Ogunyemi, K. 2009. Nigerian Languages, Ethnicity and Formal educational practices. An unpublished paper presented as part of course work for TEE 813.

Olaifa Temitope, D are Ima-Ima, Balogun Peter, Ige Oluwatosin, Adekunle D amilola \& Esther Kayode (2006). Conflict and Communication. A beokuta. Jacob \& Lydia Publishers.

Onifade, Comfort, A., Temitope Olaifa, Uche O dozor \& D avid Imhonopi 2015 Sturt ies in Arts and Social Saienes Abeokuta. Jacob \& Lydia Publishers for Communication and General Studies' D epartment, Federal University of Agriculture, Abeokuta. Nigeria. A TETFUND sponsored project.

Oyetade, S. 2003 Language planning in a multi-ethnic state: the majority/ minority dichotomy in Nigeria. NardcJamal of African Studies 12(1): 105-117.

Oyetayo, A. 2006 Nigria: Hopefor theFure Langrages of Nigeia Ibadan: Freedom Press Pruitt, D. G., \& Rubin, J. Z. (1986). Social conflict: escalation, stalemate, and settlement. New York: Random House.

Sattin, A. 2000. Brussds \& Bnuges City padk, Fodar's 1st edition, New York: Uptic Press.

Tollefson, J. W., (1991). Plaming langaage, plaminginequality. Harlow: Longman.

(Manuscipt reeived 7thFednary, 2017; accepted 14thAugust, 2017). 